\title{
Genotype-by-Environment Interaction and Yield Stability Analysis in Finger Millet (Elucine coracana L. Gaertn) in Ethiopia
}

\author{
Asfaw Adugna ${ }^{1 *}$, Tesfaye Tesso ${ }^{2}$, Erenso Degu ${ }^{1}$, Taye Tadesse ${ }^{1}$, Feyera Merga ${ }^{1}$, Wasihun Legesse ${ }^{3}$, \\ Alemu Tirfessa ${ }^{3}$, Haileselassie Kidane ${ }^{1}$, Andualem Wole ${ }^{4}$, Chemeda Daba ${ }^{5}$ \\ ${ }^{1}$ Ethiopian Institute of Agricultural Research, Melkassa Agricultural Research Center, Nazareth, Ethiopia; ${ }^{2}$ Department of Agronomy, \\ Kansas State University, Manhattan, USA; ${ }^{3}$ Ethiopian Institute of Agricultural Research Pawe Agricultural Research Center, Pawe, \\ Ethiopia; ${ }^{4}$ Amhara Agricultural Research Institute, Adet Agricultural Research Center, Adet, Ethiopia; ${ }^{5}$ Oromia Agricultural Re- \\ search Institute, Bako Agricultural Research Center, Bako, Ethiopia. \\ Email: *asfaw123@rediffmail.com
}

Received April 18 ${ }^{\text {th }}$, 2011; revised May 14 ${ }^{\text {th }}$, 2011; accepted June $11^{\text {th }}, 2011$.

\begin{abstract}
Finger millet is one of the most neglected and underutilized crops worldwide, yet an important food cereal for millions of poor farmers in Africa. An experiment was carried out to determine adaptation range of diverse set of finger millet accessions and identify superior types with excellent yield potential for use as cultivar or as germplasm source for future breeding endeavors. A total of 44 indigenous accessions selected in previous evaluations and two check varieties were tested in two sets (mixed and colored) each containing 22 entries in a total of 11 environments between 2004 and 2008 seasons. Data were collected on grain yield, days to flowering, and plant height. The result showed that $2.5 \%$, $79.1 \%$ and $18.3 \%$ of the total sum of squares in the mixed set and $2.1 \%, 86.9 \%$ and $11.0 \%$ in the colored set was attributed to genotype, environment, and genotype $\times$ environment interaction (GEI) effects, respectively. Furthermore, $54.6 \%$ and $46.19 \%$ of the GEI sum of squares in the mixed and in the colored set, respectively, were contributed by the first two interaction principal component axes (IPCA1 and IPCA2). A white seed accession (Acc. 203572) from the mixed set and three other accessions (Acc. 229469, Acc. 203410 and Acc. 203539) from the colored set were most stable and also had above average mean grain yield across environment and thus are recommended for release as cultivars to improve finger millet production in these environments.
\end{abstract}

Keywords: AMMI, Finger Millet, Genotype, Environment, Stability

\section{Introduction}

Finger millet (Elucine coracana L. Gaertn), a member of the Poaceae (Gramineae) family, is one of the most important food cereals in the sub-Saharan Africa and south Asia. It is the third most widely cultivated millets after pearl millet (Pennisetum glaucum) and foxtail millet (Setaria italica) in the semi-arid tropical and subtropical regions of the world [1]. Indigenous to eastern Africa, finger millet is widely produced in the cool high altitude areas in the region primarily as source of food and also for making traditional alcoholic beverages [2]. In Ethiopia, the crop is mainly grown in the northern, north western and western parts of the country, especially during the main rainy season. Finger millet is often mixed with other grain crops such as tef or sorghum to make composite flour for local food preparation such as injera and porridge. It is often valued as nutritious cereal by local people. This observation has scientific merit in that finger millet contains relatively higher concentration of calcium and dietary fiber than other cereals [3].

Notwithstanding its importance, published information is scarce on the agronomy and genetics of the crop. In Ethiopia, finger millet occupies $4 \%$ of the total area allocated to cereals (nearly half a million hectares) each year and also contributes about $4 \%$ to the total annual cereal grain production in the country [4]. Similar to tef, finger millet grain can be stored for several years under local storage conditions without sustaining significant damage by storage pests $[5,6]$. This property together with its adaptation to low input conditions and relatively better nutritional value [7] makes it one of the salient crops among resource poor communities living in food 
insecure areas [8]. In Ethiopia, it is often grown in poor soils without fertilizer, and thus the national average yield rarely exceeds 1 ton per hectare.

Although formal research to improve the crop has started some three decades ago, not much progress has been made because of funding limitation as the crop is not among the priority commodities. As a result, only two varieties have been identified for cultivation to date but appropriate management practices are still lacking. Though the varieties were initially released for cultivation in the sub-humid and mid altitude areas, their inadvertent introduction in to low rainfall areas found new adaptation zones. At present the production of these varieties has expanded to dry low altitude areas including regions where the crop was previously unknown [5]. Frustrated by repeated failure of the maize crop as a result of frequent drought, farmers in the dry Rift Valley region of Ethiopia widely adopted the variety that it is currently grown as one of the most important crops in this region [9].

Encouraged by the expanded adoption, the Ethiopian national sorghum research program increased its effort to identify additional high yielding varieties that can fit in to a wide range of environments. This effort drew an important lesson from past activities where extensive evaluation of hundreds of entries involving exotic sources acquired through the Eastern African Regional Sorghum and Millet (EARSAM) research network produced only limited progress. Hence, as of 2003 much of the focus was placed on evaluation of local sources for adaptation and yield potential. Superior genotypes selected from different stages of screening were pulled together and evaluated at multiple locations representing different agro-ecologies. Therefore, this paper discusses the performance of these genotypes under a range of environments and generates information on the extent of genotype-by-environment interaction which is useful in designing suitable approaches for variety selection.

\section{Materials and Methods}

The experiment was conducted from 2004 through 2008 in the main rainy seasons at four locations (Adet, Arsi Negelle, Bako and Pawe) in eleven environments. Major characteristics of the test environments are presented in Table 1.

\subsection{Genetic Materials}

A total of 44 finger millet landraces, selected from tests conducted in previous years, were evaluated in this study. The materials were grouped in to two sets each containing 22 entries. Majority of the test entries were from selections made among the 2003 observation nursery that contained a pool of landrace collections received from the Ethiopian Institute of Biodiversity Conservation (IBC). The grouping was made to reduce the number of genotypes in each set and thus maximize uniformity among experimental units. Hence, the materials were arbitrarily assigned to the two groups with the ten white seeded genotypes purposely placed in the first set to allow within group comparison among white seeded entries. This set is designated as "mixed set". All genotypes assigned to the second set have colored grains (copper, light red, dark red, brown, black) and hence were referred to as "colored set". Moreover, two released varieties (Tadesse and Padet) were included in both sets to serve as standard check.

Table 1. Major geo-climatic characteristics of the test environments.

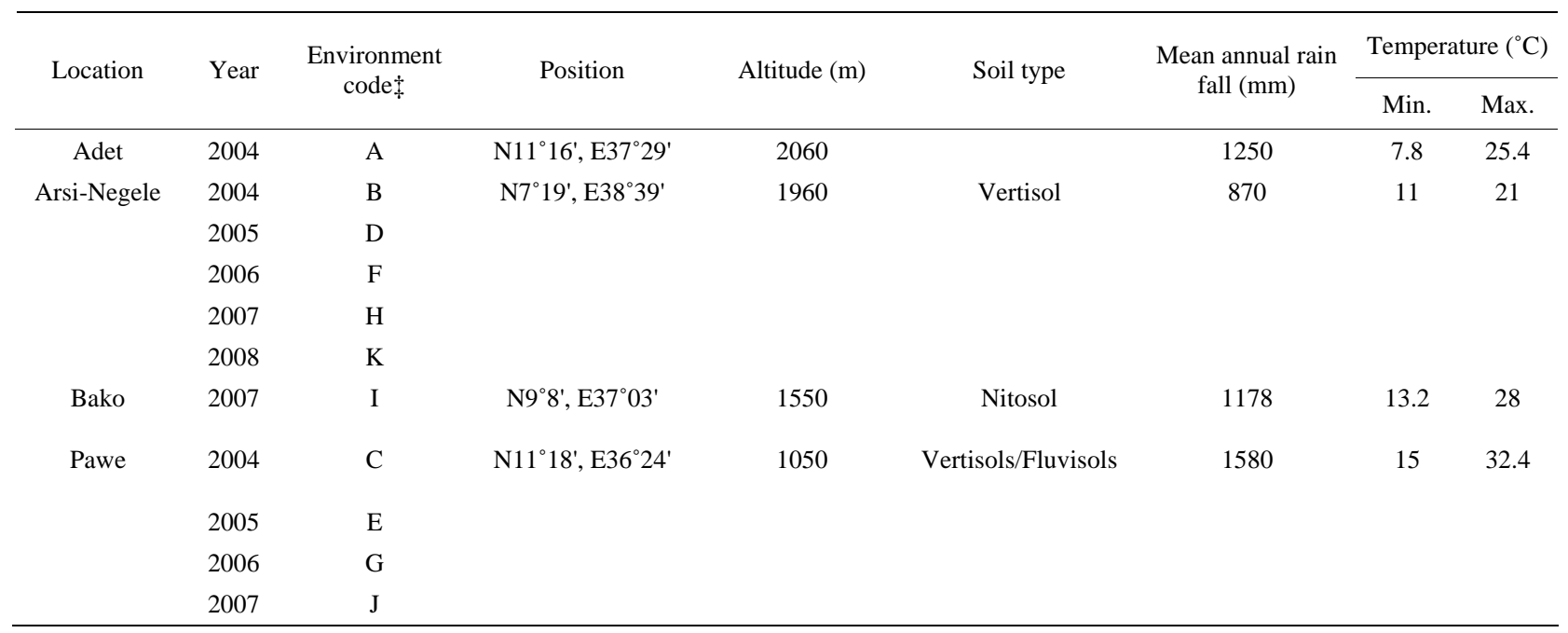

$\ddagger$ As the environments were common to both sets of trials in a single season, the codes are the same (e.g., $\mathrm{A}=\mathrm{Adet}$ in 2004 in both trials). 


\subsection{Experimental Setup}

The experiment for both sets was laid in a randomized complete block design with four replications in all locations and seasons. Because there were no recommended spacing and fertilizer rate developed for finger millet, a blanket recommendation adopted from sorghum was used. Each plot consisted of three $5 \mathrm{~m}$ long rows spaced $0.75 \mathrm{~m}$ apart. The seeds were manually drilled into each row and latter thinned to a spacing of $15 \mathrm{~cm}$ between plants. Trials in all environments received Diammonium phosphate fertilizer applied at a rate of $100 \mathrm{~kg} \cdot \mathrm{ha}^{-1}$ at planting. In order to avoid lodging, nitrogen fertilizer was not applied in all environments. The field was kept free of weeds throughout the testing seasons. Harvesting and threshing were done manually.

\subsection{Data Collection and Analysis}

Data were recorded on grain yield $\left(\mathrm{kg} \cdot \mathrm{ha}^{-1}\right)$, days to $50 \%$ flowering, (from emergence to the time when half of the plants in the plot bloomed) and plant height $(\mathrm{cm})$ (from the ground level to the tip of the longest finger) in all environments. Data on grain was recorded when the moisture content was reduced to $12.5 \%$. Moreover, the accessions were visually evaluated for their reaction to lodging and blast. The data were subjected to analysis of variance (ANOVA) for each of the environments and for the combined data using SAS 9.1 (SAS Institute). Moreover, Additive Main Effects and Multiplicative Interaction (AMMI) ANOVA and AMMI biplot were performed using CropStat 7.2 Software [10]. The additive main effects and multiplicative interaction (AMMI) model is a multivariate approach proposed to dissect the GEI in to two main components. The first component is the ANOVA, which is the additive component and the second is the interaction principal components [11]. The AMMI 1 biplot contains main effect (genotype/environment) means in the $\mathrm{x}$-axis and the first interaction principal component axis (IPCA 1) in the y-axis such that genotypes and/or environments that appear in a perpendicular line have similar means and those that appear on a horizontal line have similar interaction patterns [12]. Further, stable genotypes (with less GEI) are those, which have IPCA 1 values closer to zero regardless of their sign. Therefore, the best genotypes are those, which are placed on the right side of the AMMI 1 biplot origin (the junction of IPCA 1 at zero and the average mean yield) marked at or closer to the IPCA 1 origin (zero).

\section{Results}

\subsection{Grain Yield and Phenology}

The AMMI ANOVA for the combined data is presented in Table 2. Genotype, environment, genotype $\times$ environment interaction effects were significant for grain yield and days to flowering in both sets. In the mixed set experiment, $2.5 \%, 79.1 \%$, and $18.3 \%$ of the total sum of squares was attributed to genotypes, environments, and genotype $\times$ environment interaction effects. The result for the colored set was also similar to the mixed set and showed that much of the observed variability (86.9\%) was attributed to the environmental variance and only $2.08 \%$ and $11.02 \%$ of the total sum of square for yield could be explained in terms of genotype and genotype $x$ environment interaction, respectively.

Table 2. Analysis of variance for the AMMI model for grain yield.

\begin{tabular}{|c|c|c|c|c|c|}
\hline \multirow{2}{*}{ Source of variation } & \multirow{2}{*}{ D.F. } & \multicolumn{2}{|c|}{ Mixed set } & \multicolumn{2}{|c|}{ Colored set } \\
\hline & & S.S. & $\%$ contribution & S.S. & \% contribution \\
\hline Environments (E) & 10 & 269182000 & 79.13 & 318627000 & 86.90 \\
\hline IPCA 1 & 32 & 24182100 & 38.75 & 11504100 & 28.47 \\
\hline IPCA 2 & 30 & 9858900 & 15.80 & 7156500 & 17.71 \\
\hline IPCA 3 & 28 & 8486000 & 13.60 & 6506620 & 16.10 \\
\hline IPCA 4 & 26 & 6609360 & 10.59 & 5684490 & 14.07 \\
\hline $\mathrm{G} \times \mathrm{E}$ residual & 114 & 13266000 & & 9551830 & \\
\hline Total & 263 & 340184000 & & 366662000 & \\
\hline
\end{tabular}


The mean grain yield of genotypes included in the mixed set ranged from $2074 \mathrm{~kg} \cdot \mathrm{ha}^{-1}$ to $2804 \mathrm{~kg} \cdot \mathrm{ha}^{-1}$ in Acc. 203523 and Acc. 203564, respectively. Fourteen of the 24 genotypes had above average yield, but only Acc. 203564 had significantly higher yield than the entry mean (2541 $\mathrm{kg} \cdot \mathrm{ha}^{-1}$ ) (Table 3). Moreover, in the same set, mean grain yield among environments ranged from $1230 \mathrm{~kg} \mathrm{ha}^{-1}$ to $4416 \mathrm{~kg} \cdot \mathrm{ha}^{-1}$ in E and B in that order. Yield at six of the eleven environments was higher than average.

In the colored set, genotype yield ranged from 2369 $\mathrm{kg} \cdot \mathrm{ha}^{-1}$ in Acc. 203319 to $3217 \mathrm{~kg} \cdot \mathrm{ha}^{-1}$ in Acc. 203539. Eleven of the 24 genotypes included in this set showed above average performance (Table 4). However, only three of them: Acc. 229469, Acc. 203410, and Acc.
203539, had significantly higher yield than the entry mean. Seven and three of the genotypes in this set out yielded the check varieties Tadesse and Padet, respectively. Similarly, the mean yield among the environments ranged from 1479 $\mathrm{kg} \cdot \mathrm{ha}^{-1}$ in G to $4698 \mathrm{~kg} \cdot \mathrm{ha}^{-1}$ in B. Only four of the eleven environments, B, D, F and K, supported yields significantly higher than the overall mean. In both sets of experiments, the standard variety Padet out yielded the other standard Tadesse. In several locations, accessions in both sets had yields that were significantly higher than both standard varieties but none of the across location mean yield of the mixed set genotypes was significantly higher than the standard varieties.

Table 3. Mean grain yield $\left(\mathrm{Kg} \cdot \mathrm{ha}^{-1}\right)$, days to $50 \%$ flowering (DTF), plant height $(\mathrm{PH})$, and the joint regression (bi) of the mixed set finger millet landrace accessions tested in 11 environments.

\begin{tabular}{|c|c|c|c|c|c|c|c|c|c|c|c|c|c|c|c|}
\hline \multirow{2}{*}{ Genotypes** } & \multicolumn{12}{|c|}{ Grain yield-by-environment } & \multirow{2}{*}{ DTF } & \multirow{2}{*}{$\mathrm{PH}$} & \multirow{2}{*}{ bi } \\
\hline & A & $\mathrm{B}$ & $\mathrm{C}$ & $\mathrm{D}$ & $\mathrm{E}$ & $\mathrm{F}$ & G & $\mathrm{H}$ & $\mathrm{I}$ & $\mathrm{J}$ & $\mathrm{K}$ & Mean & & & \\
\hline 2. Acc. 229349(W) & 2441 & 4347 & 1948 & 2289 & 828 & 3976 & 349 & 4433 & 1060 & 737 & 2311 & 2247 & 97 & 106.7 & $1.35^{*}$ \\
\hline 3. Acc. 229367 & 1817 & 4222 & 2587 & 3467 & 1694 & 4678 & 950 & 3400 & 1666 & 1835 & 2911 & 2657 & 96 & 106.1 & 1.02 \\
\hline 5. Acc. 229401 & 1947 & 4378 & 2504 & 2911 & 1498 & 3456 & 1661 & 3867 & 2791 & 2140 & 2822 & 2725 & 98 & 100.1 & 0.79 \\
\hline 6. Acc. 229463(W) & 2638 & 4511 & 2069 & 2578 & 405 & 3484 & 1788 & 4711 & 1821 & 826 & 2667 & 2500 & 101 & 112.2 & 1.19 \\
\hline 7. Acc. 229465(W) & 2711 & 4711 & 2138 & 1533 & 922 & 4011 & 1275 & 2622 & 585 & 1607 & 3389 & 2319 & 99 & 110.5 & 1.10 \\
\hline 8. Acc. 229470 & 2648 & 5156 & 2279 & 2889 & 373 & 3444 & 2874 & 4133 & 1242 & 1084 & 2800 & 2629 & 97 & 107.3 & 1.16 \\
\hline 9. Acc. 203358(W) & 2406 & 4667 & 2068 & 2245 & 470 & 3356 & 1296 & 3933 & 675 & 2333 & 3000 & 2404 & 100 & 111.1 & 1.13 \\
\hline 11. Acc. 203509 & 2172 & 4644 & 2562 & 2578 & 1733 & 3416 & 1389 & 3933 & 2192 & 1867 & 2889 & 2670 & 97 & 98.9 & 0.90 \\
\hline 12. Acc. 203523 & 1778 & 4067 & 716 & 1667 & 988 & 4133 & 1059 & 2933 & 1637 & 1702 & 2133 & 2074 & 100 & 108.0 & 0.99 \\
\hline 13. Acc. $203530(\mathrm{~W})$ & 2251 & 4578 & 1775 & 2378 & 451 & 3544 & 2535 & 4644 & 1976 & 1000 & 2978 & 2555 & 102 & 117.3 & 1.12 \\
\hline 14. Acc. 203542 & 2448 & 4867 & 2584 & 3000 & 1946 & 3817 & 1285 & 3533 & 1933 & 2025 & 2644 & 2735 & 97 & 102.4 & 0.93 \\
\hline 15. Acc. 203562 & 2298 & 4356 & 2371 & 3133 & 1685 & 2944 & 937 & 3222 & 2380 & 1732 & 2911 & 2543 & 96 & 98.4 & 0.78 \\
\hline 16. Acc. 203564 & 2427 & 4667 & 2527 & 3200 & 1906 & 4311 & 1557 & 3489 & 2531 & 1753 & 2478 & 2804 & 97 & 105.8 & 0.91 \\
\hline 17. Acc. 203572(W) & 2866 & 5280 & 2102 & 3355 & 996 & 4491 & 1409 & 2667 & 1474 & 1756 & 3089 & 2680 & 96 & 98.7 & 1.16 \\
\hline 18. Acc. 203587(W) & 2719 & 4778 & 2073 & 1778 & 411 & 5344 & 1446 & 3900 & 1807 & 979 & 2622 & 2532 & 99 & 112.5 & $1.39 *$ \\
\hline 19. Acc. 203558 & 2227 & 4778 & 2590 & 2778 & 1649 & 4156 & 921 & 3751 & 1851 & 1286 & 2378 & 2578 & 97 & 105.9 & 1.11 \\
\hline 20. Acc. 215986 & 1714 & 3111 & 3053 & 1578 & 2451 & 3700 & 1452 & 2711 & 2468 & 2131 & 2456 & 2439 & 102 & 94.8 & $0.40^{*}$ \\
\hline 21. Асc. 215869(W) & 2780 & 4244 & 2228 & 1889 & 650 & 3867 & 1266 & 4033 & 1755 & 781 & 2867 & 2396 & 101 & 109.5 & 1.15 \\
\hline 23. Tadesse & 2541 & 3622 & 1749 & 3556 & 1983 & 3804 & 1599 & 3356 & 1819 & 2092 & 2822 & 2631 & 97 & 108.0 & $0.69 *$ \\
\hline 24. Padet & 2358 & 3822 & 3008 & 2734 & 1832 & 3422 & 2024 & 3200 & 1917 & 2155 & 3044 & 2683 & 97 & 105.9 & $0.60 *$ \\
\hline Mean & 2372 & 4416 & 2255 & 2605 & 1230 & 3886 & 1454 & 3660 & 1736 & 1577 & 2760 & 2541 & 98 & 105.8 & \\
\hline LSD (0.05) & 477.3 & 1288 & 497 & 927 & 321 & 1578 & 617 & 966 & 668 & 393 & 802.6 & 258 & 8 & 9.0 & \\
\hline CV (\%) & 14.25 & 20.68 & 15.6 & 25.2 & 18.5 & 28.8 & 30.1 & 18.7 & 27.2 & 17.6 & 20.6 & 24 & 5 & 12.7 & \\
\hline
\end{tabular}

*slopes significantly different from 1.00 (the slope for the overall regression), **W $=$ accessions with white kernel color, the rest are brown. 
Table 4. Mean grain yield $\left(\mathrm{Kg}_{\mathrm{ha}} \mathrm{h}^{-1}\right)$, days to $50 \%$ flowering (DTF), plant height (PH), and the joint regression (bi) of the colored set finger millet landrace accessions tested in 11 environments.

\begin{tabular}{|c|c|c|c|c|c|c|c|c|c|c|c|c|c|c|c|}
\hline \multirow{2}{*}{ Genotypes } & \multicolumn{12}{|c|}{ Grain yield-by-environment } & \multirow{2}{*}{ DTF } & \multirow{2}{*}{ PH } & \multirow{2}{*}{ bi } \\
\hline & A & B & $\mathrm{C}$ & $\mathrm{D}$ & E & F & G & $\mathrm{H}$ & I & $\mathrm{J}$ & $\mathrm{K}$ & Mean & & & \\
\hline 1. Acc. 229376 & 2497 & 4311 & 3063 & 5211 & 1789 & 4220 & 1397 & 2228 & 1954 & 2056 & 3400 & 2921 & 93 & 101.5 & 1.02 \\
\hline 2. Acc. 229381 & 2147 & 4578 & 2661 & 4833 & 1846 & 3505 & 1364 & 2484 & 1194 & 2082 & 2867 & 2687 & 93 & 103.0 & 0.987 \\
\hline 3. Acc. 229383 & 2604 & 4045 & 2292 & 4022 & 2027 & 4322 & 1527 & 1984 & 1666 & 2258 & 3578 & 2757 & 91 & 100.5 & 0.857 \\
\hline 4. Acc. 229398 & 2902 & 4156 & 2482 & 5411 & 1389 & 4267 & 1113 & 1774 & 1433 & 1760 & 2911 & 2691 & 93 & 108.0 & 1.175 \\
\hline 5. Асc. 229399 & 2652 & 4867 & 2027 & 4722 & 1568 & 4071 & 1561 & 2058 & 2791 & 2289 & 3245 & 2895 & 91 & 101.4 & 0.982 \\
\hline 6. Асc. 229400 & 2630 & 3978 & 2727 & 4045 & 2414 & 3665 & 2439 & 2405 & 1821 & 2262 & 2289 & 2788 & 91 & 99.8 & $0.594 *$ \\
\hline 7. Acc. 229407 & 2792 & 4489 & 2643 & 4244 & 2417 & 4253 & 1304 & 2042 & 585 & 2754 & 2867 & 2763 & 94 & 101.4 & 0.971 \\
\hline 8. Acc. 229415 & 2944 & 4845 & 2207 & 4445 & 2485 & 3933 & 1770 & 2093 & 1242 & 2686 & 3156 & 2891 & 94 & 104.4 & 0.941 \\
\hline 9. Асc. 229417 & 2876 & 5289 & 2256 & 4889 & 1990 & 4400 & 1106 & 1670 & 595 & 2162 & 3622 & 2805 & 92 & 99.5 & $1.318^{*}$ \\
\hline 10. Acc. 229440 & 2884 & 5178 & 2054 & 4873 & 1455 & 3613 & 1759 & 1459 & 2022 & 1824 & 1956 & 2643 & 88 & 105.4 & 1.088 \\
\hline 11. Acc. 229442 & 2797 & 4933 & 2264 & 4800 & 1723 & 3467 & 1276 & 1444 & 2192 & 1982 & 3334 & 2746 & 94 & 110.1 & 1.068 \\
\hline 12. Acc. 229458 & 3172 & 4511 & 2416 & 4667 & 2080 & 3896 & 1399 & 1340 & 1629 & 2311 & 3556 & 2816 & 93 & 104.7 & 1.026 \\
\hline 13. Асc. 229461 & 3199 & 4978 & 2437 & 4211 & 2098 & 4200 & 1340 & 2120 & 1975 & 2630 & 3000 & 2926 & 94 & 106.6 & 0.95 \\
\hline 14. Acc. 229462 & 2842 & 4022 & 2206 & 4613 & 2164 & 3136 & 1603 & 2025 & 1933 & 2451 & 3000 & 2727 & 90 & 104.6 & $0.774 *$ \\
\hline 15. Acc. 229468 & 2909 & 5222 & 2093 & 4545 & 1940 & 3422 & 1422 & 1616 & 2379 & 2172 & 3289 & 2819 & 92 & 109.0 & 1.011 \\
\hline 16. Acc. 229469 & 2810 & 5022 & 2303 & 5656 & 1840 & 4244 & 1537 & 1719 & 2827 & 1911 & 3533 & 3036 & 91 & 111.6 & 1.169 \\
\hline 17. Acc. 203410 & 3330 & 4756 & 2534 & 5444 & 2086 & 4045 & 1403 & 2246 & 1474 & 2239 & 4089 & 3059 & 92 & 104.6 & 1.142 \\
\hline 18. Асc. 203539 & 3100 & 5511 & 2541 & 4578 & 3627 & 3847 & 1247 & 2334 & 1807 & 3572 & 3222 & 3217 & 90 & 85.5 & 0.914 \\
\hline 19. Асc. 203289 & 2767 & 4267 & 2005 & 4656 & 1742 & 3247 & 1356 & 1887 & 1851 & 2489 & 2978 & 2658 & 94 & 99.0 & 0.895 \\
\hline 20. Aсc. 203300 & 2347 & 4511 & 2067 & 4456 & 1835 & 4531 & 1632 & 1708 & 2468 & 750 & 2800 & 2646 & 95 & 103.4 & 1.02 \\
\hline 21. Acc. 215961 & 2341 & 4134 & 2301 & 4889 & 1746 & 4045 & 1538 & 1709 & 1460 & 1853 & 3156 & 2652 & 94 & 99.2 & 1.026 \\
\hline 22. Асc. 203319 & 2759 & 5200 & 2138 & 3111 & 898 & 3756 & 1740 & 1434 & 830 & 1180 & 3011 & 2369 & 93 & 106.9 & 1.048 \\
\hline 23. Tadesse & 2623 & 5022 & 2403 & 4434 & 1621 & 3356 & 1471 & 1429 & 1819 & 1636 & 2822 & 2603 & 92 & 106.8 & 1.038 \\
\hline 24. Padet & 2661 & 4934 & 2763 & 3933 & 1608 & 4225 & 1201 & 1820 & 1917 & 2196 & 3045 & 2755 & 95 & 102.1 & 0.99 \\
\hline Mean & 2774 & 4698 & 2370 & 4612 & 1933 & 3903 & 1479 & 1876 & 1744 & 2146 & 3113 & 2786 & 93 & 103.3 & \\
\hline LSD (0.05) & 495 & 865 & 618 & 1110 & 457 & 1235 & 591 & 613 & 653 & 494 & 915 & 232 & 3 & 6.6 & \\
\hline CV (\%) & 12.62 & 13.04 & 18.5 & 17 & 16.8 & 22.4 & 28.3 & 23.1 & 26.5 & 16.3 & 20.8 & 19.65 & 3 & 9.8 & \\
\hline
\end{tabular}

*Slopes significantly different from 1.00 (the slope for the overall regression).

Days to flowering ranged from 96 to 102 in the mixed set, and from 88 to 95 in the colored set. Similarly, the range for plant height was $94.5 \mathrm{~cm}$ to $117.3 \mathrm{~cm}$ in the mixed set and $85.5 \mathrm{~cm}$ to $111.6 \mathrm{~cm}$ in the colored set. Plant height $(\mathrm{r} 1=-0.36, \mathrm{r} 2=-0.34)$ and days to flowering $(\mathrm{r} 1=-0.53, \mathrm{r} 2=-0.23)$ were found to have negative correlation with grain yield.

\subsection{Response and Stability of the Landraces}

Genotypes, Acc. 229349 and Acc. 203587 from the mixed set had linear regression coefficient significantly higher than 1.0 (the overall regression) and hence were highly responsive to the suitable environments (Table 3). However, since they are tall accessions (Table 2), adding more inputs may enhance lodging. On the other hand, Acc. 215986, Tadesse and Padet had slopes significantly lower than 1.0 and hence were better adapted to marginal environments.

The AMMI analysis showed that all of the 4 principal component axes were significant in both sets. However, $54.6 \%$ and $46.19 \%$ of the GEI sum of squares in the mixed set and in the colored set, respectively, were contributed by the first two interaction principal components (IPCA1 and IPCA2). Five accessions in the mixed set, Acc. 
229465, Acc. 203509, Acc. 203523, Acc. 203572, and Acc. 203558 were shown to have the highest stability as revealed by their relative position with respect to the biplot origin (Figure 1). However, none of these accessions had significantly higher yield than the overall entry mean and the check varieties. Among the colored set, five accessions, Acc. 229458, Acc. 203410, Acc. 203289, Acc. 215961, Acc. 203319, and the check variety Padet showed better stability than the rest of the entries (Figure 2). Again none of these accessions did exceed the standard checks except Acc. 203410 that produced significantly higher yield than both check varieties. This accession is also within the same range of maturity (days to flowering) and height group with that of the standard varieties.

\section{Discussion}

In general, the genotypic variation in the studied traits was considerably narrow probably because of the rigorous selection process conducted in the previous year which might have not intentionally targeted these traits. The influence of GEI resulted in variable performance of the genotypes in the different test environments. Varieties with high levels of heterozygosity and/or heterogeneity are less sensitive to environmental variation and are, therefore, more stable-yielding. On the other hand, the Elucines generally are reported to be strictly autogamous with low levels of heterozygosity. This is perhaps the major factor that contributed to the high GEI in finger millet in the present study.

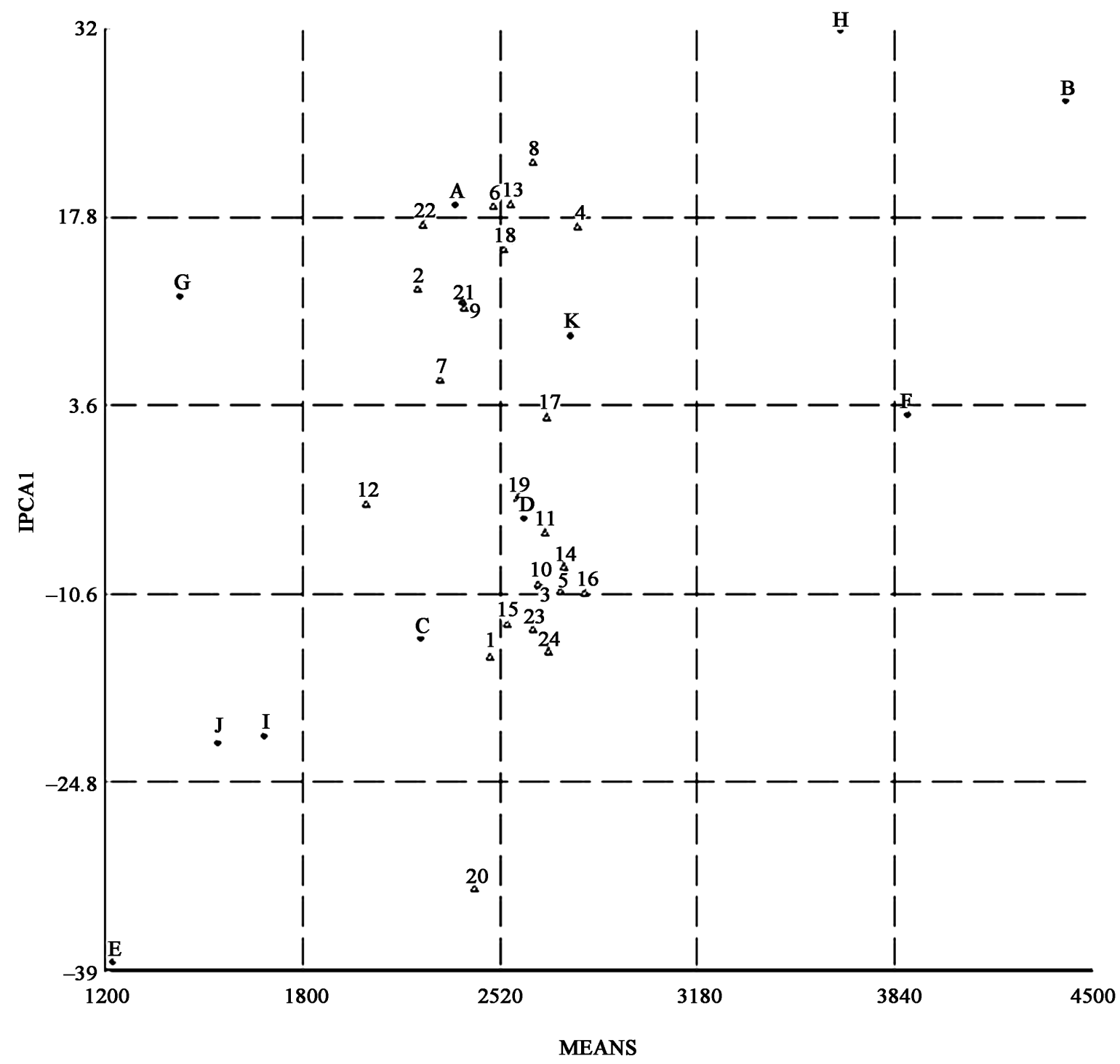

Figure 1. AMMI 1 Biplot of the 24 finger millet varieties and the 11 test environments in the mixed set. 


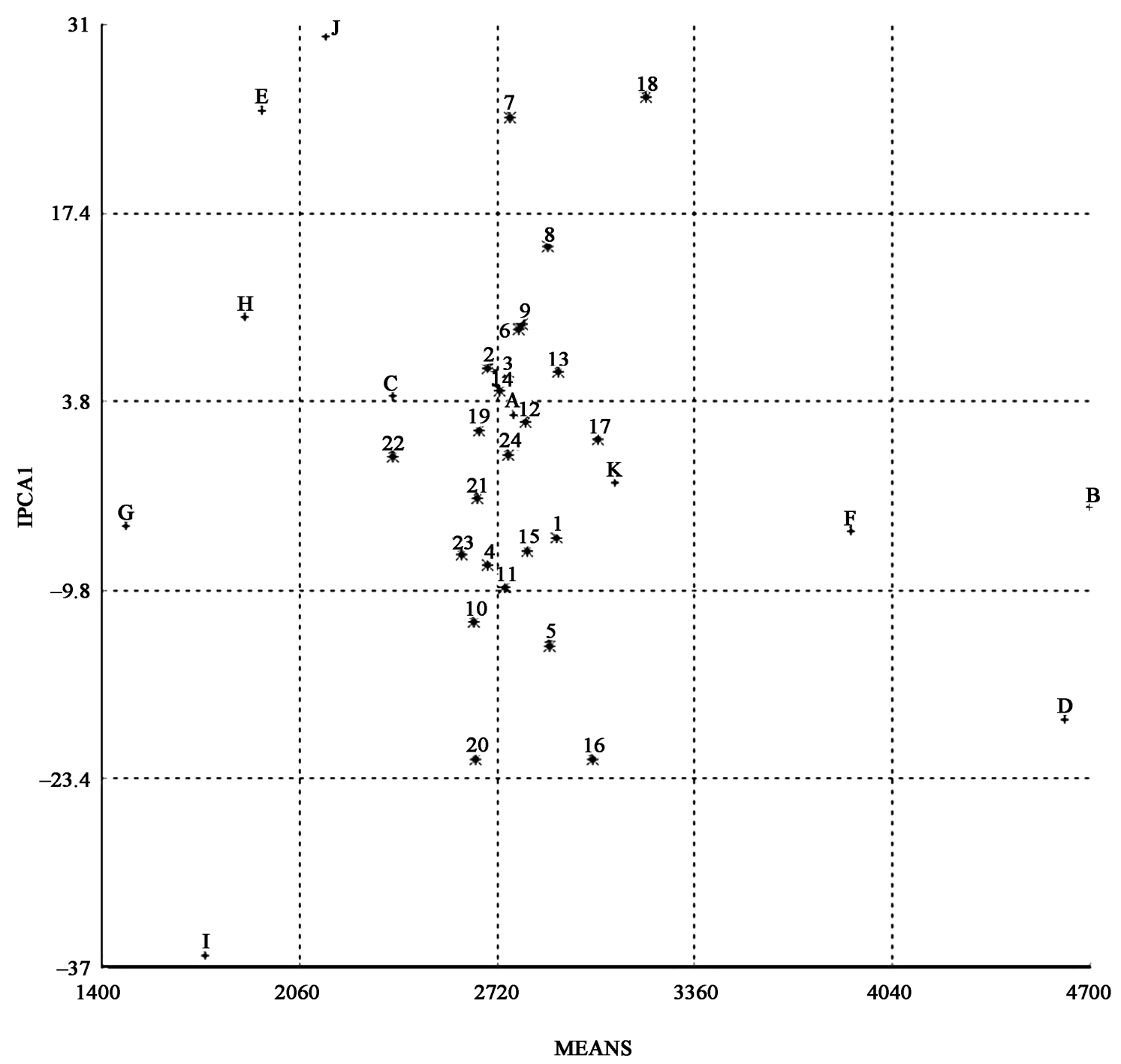

Figure 2. AMMI1 Biplot of the 24 finger millet varieties and the 11 test environments in the colored set.

While positive correlation between days to flowering/maturity and yield seems to be a common phenomenon in crop plants, the negative correlation in the present experiment was perhaps due to the concomitant occurrence of late flowering with the suitable period of fungal (blast) infection that reduces yield. Moreover, the negative correlation between plant height and grain yield might be due to lodging. Taller plants tend to lodge more than shorter ones and lose their yield. Some of the testing sites (especially Pawe and Bako) have high rainfall and high temperature, which is suitable for the development of fungal diseases like blast (Pyricularia spp.) that reduce yield more on the lodged plants.

Various models to measure stability of genotype performance across multi-environments are available in literature. At present, the most widely used model is
AMMI, which involves both ANOVA and principal component analysis to dissect GEI into the causes of variation. However, stability per se is not necessarily a positive factor and it is desirable only when associated with a high mean yield (Yan and Hunt, 2002). In the present experiment, a white seed accession (Acc. 203572) from the mixed set and three other accessions (Acc. 229469, Acc. 203410 and Acc. 203539) from the colored set were found to be most stable based on the AMMI model and also had above average mean grain yield across environments and thus are recommended for release as cultivars to contribute for enhanced finger millet production in these environments. The response of Tadesse to the poor environments in the first set was in agreement with the previous observation during the scaling up activity in the dry lowland areas of the Ethiopian 
rift valley (Siraro and Alaba). However, a similar response was not observed in the other set because coefficient of joint regression $\left(b_{i}\right)$ is a relative measure, which varies with the genotypes included in the set [13].

In the past decade, 2001-2010, finger millet production area in Ethiopia increased from 342,120 ha to 368,999 ha with an increase of $7.3 \%$, and the production increased from 3,769,290 to 5,241,911 quintals with a proportion of $28 \%[4,14]$. This was partly due to the adoption of improved varieties and production practices or possibly an indication of the fact that agriculture is being pushed to the more marginal areas due to the associated change in climate demanding adaptable crops. Thus, a continuous supply of high yielding varieties that have stable performance in a wide range of environments is needed for sustainable production. To this end, we believe that the 4 genotypes selected in this experiment will have significant contribution to enhance production in areas where there is similar agro-climatic conditions with the test environments.

In conclusion, east Africa is reported to be a region of contrasts, where Africa's lowest and highest elevations are found; the differences of which coupled with the differences in rainfall and temperature over short geographic distances provided varying environments suitable for crop diversification, early domestication and subsequent cultivation of landraces. In Ethiopia, diverse forms of finger millet landraces are found in altitude ranges of around $500 \mathrm{~m}$ (e.g. Chikumbo) to $2500 \mathrm{~m}$ (e.g. South Gondar). However, selection of high yielding and stable genotypes in nation wide multi-environments has not been successful. While finger millet can be a potential cereal for food security under the rapidly changing climate, alleviating its constraints will remain a challenging task for the researchers. In addition to the prevailing production constraints of finger millet, which are mainly related to poor management practices, some more are still emerging. For instance, in northern Ethiopia, the parasitic weed, Striga spp. is expanding its host range from maize and sorghum, its principal hosts to small cereals, tef and finger millet. Hence, exhaustive work should be done on identifying the landraces and side by side introduction and evaluation of exotic germplasm. Moreover, no agronomic recommendations such as spacing and fertilizer rate are available to date for finger millet in the country. Therefore, multidisciplinary work is binding in order to break the yield barriers and to reap the potential from these untapped genetic resources.

\section{Acknowledgements}

We thank the sorghum and millets technical staff at Melkassa, Arsi Negelle, Pawe, Adet and Bako Research Centers.

\section{REFERENCES}

[1] V. G. Reddy, H. D. Upadhyaya, C. L. L. Gowda and S. Singh, "Characterization of Eastern African Finger Millet Germplasm for Qualitative Quantitative Characters at ICRISAT," Journal of SAT Agricultural Research, Vol. 7, 2009.

[2] ICRISAT and FAO, "The World Sorghum and Millet Economies: Facts, Trends and Outlook,” ICRISAT, Andhra Pradesh, 1996.

[3] A. Wondimu and F. Tekabe, "Utilization of Teff in the Ethiopian Diet,” In: H. Tefera, G. Belay and M. Sorrells, Eds., Proceedings of the International Workshop on Tef Genetics and Improvement, Debre Zeit, 2001.

[4] Central Statistical Agency (CSA), "Agricultural Sample Survey,” Report on Area and Production of Crops (Private Peasant Holdings, Meher Season), Statistical Bulletin 446, Addis Ababa, May 2010.

[5] A. Adugna, "The Role of Introduced Sorghum and Millets in Ethiopian Agriculture,” Journal of SAT Agricultural Research, Vol. 3, December 2007.

[6] E. Degu, A. Adugna, T. Tadesse, and T. Tesso, "Genetic Resources Breeding and Production of Millets in Ethiopia," In: Z. Tadele, Ed., New Approaches to Plant Breeding of Orphan Crops in Africa: Proceedings of an International Conference, Bern, 19-21 September 2007, pp. 43-56.

[7] M. H. Mengesha, K. E. Prasada Rao and S. Appa Rao, "Genetic Diversity of Sorghum and Millets in Eastern Africa,” 6th Edition, Eastern African Research on Sorghum and Millets Workshop, Mogadishu, 1988.

[8] National Research Council (NRC), "Lost Crops of Africa,” Grains: Board on Science and Technology for International Development, National Academy Press, Washington D. C., Vol. 1, 1996.

[9] C. Anchala, H. Kidane and T. Mulatu, "Impacts of Improved Finger Millet Technology Promotion in the Central Rift Valley of Ethiopia,” In: T. Abate ed., Success with Value Chain, Ethiopian Institute of Agricultural Research, Addis Ababa, 2006, pp. 129-140.

[10] International Rice Research Institute (IRRI), “CropStat for Windows 7.2,” Dapo, Metro Manila, 2007.

[11] R. W. Zobel, M. J. Wright and H. G. Gauch Jr., "Statistical Analysis of a Yield Trial,” Agronomy Journal, Vol. 80, 1988, pp. 388-393.

[12] J. Crossa, H. G. Gauch and R. W. Zobel, “Additive Main Effects and Multiplicative Interaction Analysis of Two International Maize Cultivar Trials," Crop Science, Vol. 30, No. 3, 1990, pp. 493-500. doi:10.2135/cropsci1990.0011183X003000030003x

[13] A. Adugna, "Assessment of Yield Stability in Sorghum Using Univariate and Multivariate Statistical Approaches,” Hereditas, Vol. 145, 2008, pp. 28-37.

[14] Central Statistical Agency (CSA), "Agricultural Sample Survey,” Report on Area and Production of Crops for Private Peasant Holdings, Meher Season, Addis Ababa, 2001. 